\title{
The synergistic radiosensitizing effect of tirapazamine-conjugated gold nanoparticles on human hepatoma HepG2 cells under $\mathrm{X}$-ray irradiation
}

\author{
Xi Liul-4 \\ Yan Liu ${ }^{1-4}$ \\ Pengcheng Zhangl-4 \\ Xiaodong Jin ${ }^{1-3}$ \\ Xiaogang Zheng ${ }^{1-4}$ \\ Fei Ye ${ }^{1-4}$ \\ Weiqiang Chen ${ }^{1-3}$ \\ Qiang $\mathrm{Li}^{1-3}$ \\ 'Institute of Modern Physics, ${ }^{2}$ Key \\ Laboratory of Heavy lon Radiation \\ Biology and Medicine, Chinese \\ Academy of Sciences, ${ }^{3}$ Key Laboratory \\ of Basic Research on Heavy lon \\ Radiation Application in Medicine, \\ Gansu Province, Lanzhou, ${ }^{4}$ School of \\ Life Science, University of Chinese \\ Academy of Sciences, Beijing, People's \\ Republic of China
}

Correspondence: Weiqiang Chen

Qiang Li

Institute of Modern Physics, Chinese Academy of Sciences, No 509 Nanchang Road, Chengguan District, Lanzhou, Gansu Province, People's Republic of China

Tel +86931 4969316

Email chenwq7315@impcas.ac.cn;

liqiang@impcas.ac.cn

\author{
This article was published in the following Dove Press journal: \\ International Journal of Nanomedicine \\ 28 July 2016 \\ Number of times this article has been viewed
}

\begin{abstract}
Reductive drug-functionalized gold nanoparticles (AuNPs) have been proposed to enhance the damage of X-rays to cells through improving hydroxyl radical production by secondary electrons. In this work, polyethylene glycol-capped AuNPs were conjugated with tirapazamine (TPZ) moiety, and then thioctyl TPZ (TPZs)-modified AuNPs (TPZs-AuNPs) were synthesized. The TPZs-AuNPs were characterized by transmission electron microscopy, ultraviolet-visible spectra, dynamic light scattering, and inductively coupled plasma mass spectrometry to have a size of $16.6 \pm 2.1 \mathrm{~nm}$ in diameter and a TPZs/AuNPs ratio of $\sim 700: 1$. In contrast with PEGylated AuNPs, the as-synthesized TPZs-AuNPs exhibited 20\% increment in hydroxyl radical production in water at $2.0 \mathrm{~Gy}$, and $19 \%$ increase in sensitizer enhancement ratio at $10 \%$ survival fraction for human hepatoma HepG2 cells under X-ray irradiation. The production of reactive oxygen species in $\mathrm{HepG} 2$ cells exposed to X-rays in vitro demonstrated a synergistic radiosensitizing effect of AuNPs and TPZ moiety. Thus, the reductive drugconjugated TPZs-AuNPs as a kind of AuNP radiosensitizer with low gold loading provide a
\end{abstract} new strategy for enhancing the efficacy of radiation therapy.

Keywords: AuNPs, radiation enhancement, synergistic effect, human hepatoma cells, hydroxyl radical production

\section{Introduction}

The estimates of the worldwide incidence and mortality of all cancers have showed that there were 14.1 million new cases and 8.2 million deaths in $2012 .{ }^{1}$ Cancer now causes more deaths than all coronary heart diseases or strokes, and has apparently become the leading threat to human health. Radiation therapy is one of the primary modalities of cancer treatment, which provide relieve from symptoms of advanced or metastatic diseases, and is the need of $>50 \%$ of cancer patients. ${ }^{2}$ The major challenge of radiation therapy is maximizing the radiation dose delivered to malignant tissues while minimizing damage to the surrounding normal tissues. ${ }^{3-5}$ Improving the efficacy of radiation therapy, like enhancing the radiation effects by increasing the dose specifically to the tumor cells, can benefit a significant number of patients. ${ }^{6,7}$

One way of improving the efficacy of radiation therapy is by expanding photon/ Auger electron induction in the physical/chemical stage during irradiation, which will lead to enhancement in reactive oxygen species (ROS) production and subsequently the radiobiological response. ${ }^{8}$ The interaction of ionizing radiation with high- $Z$ 
A
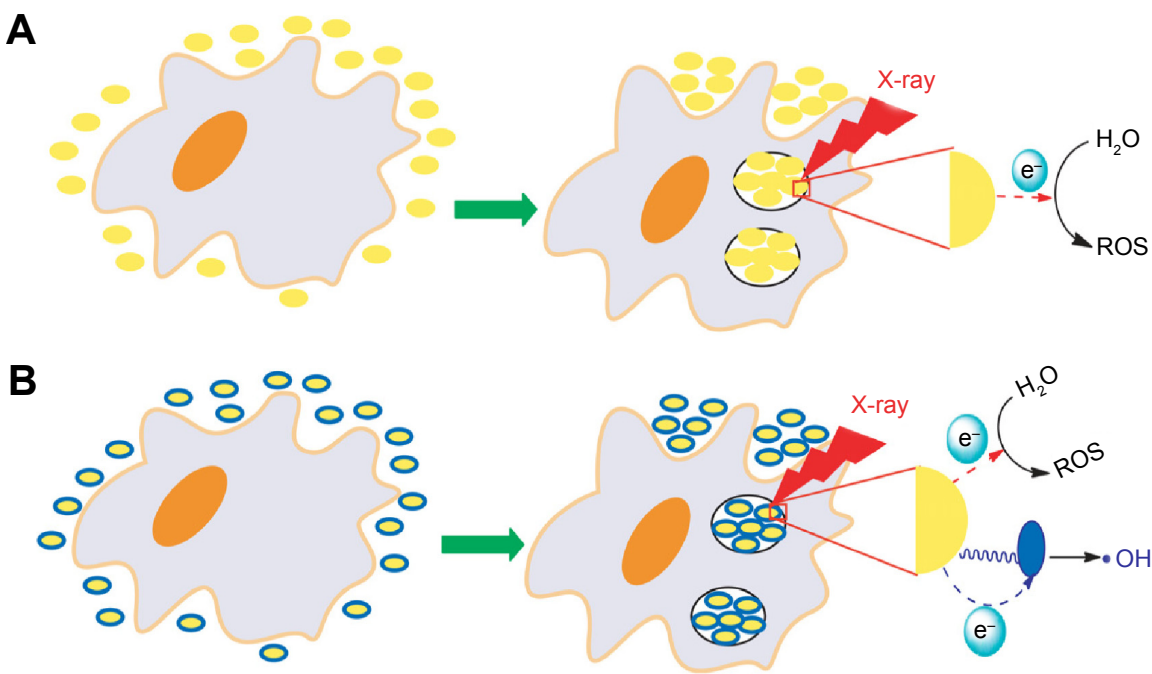

Figure I Radiosensitizing principle of drug-modified gold nanoparticles.

Notes: Radiosensitizing principle of nanoparticles based on (A) gold- and (B) drug-mediated radiosensitization.

Abbreviation: ROS, reactive oxygen species.

(atomic number) materials may result in enhancement of Auger electron emission. When iodine was first used to sensitize cultured cells by Matsudaira et al in 1980, the concept of using high- $Z$ materials to increase the radiation dose given to a tumor during radiation therapy was proposed. ${ }^{9}$ Noble metal nanoparticles have had diverse applications in cancer therapy, such as diagnostics ${ }^{10,11}$ and treatment reagents, ${ }^{12}$ in the last decade. Since the in vivo study on the radiationenhancing effect of gold nanoparticles (AuNPs) was presented by Hainfeld et al in 2004, ${ }^{13}$ gold,${ }^{14-16}$ platinum, ${ }^{17}$ and bismuth $^{18,19}$ nanoparticles have been proposed as radiation sensitizers under irradiation of X-rays, $\gamma$-rays, and electron beams in extensive investigations. Owing to high biocompatibility, facile conjugation with tumor-targeting agents, and high X-ray absorption coefficients, AuNPs have become the primary option for radiation enhancement. ${ }^{20-22}$

In this study, we investigated the radiosensitizing effect of AuNPs under high-linear energy transfer particle radiation as well as low-linear energy transfer conventional radiation. ${ }^{23,24}$ AuNPs internalized by cells were found in endosomes/ lysosomes instead of nuclei. As a possible mechanism, the dose enhancement in the presence of AuNPs could be attributed to additional photoelectrons and Auger electrons generated from nanoparticles under X-ray irradiation. Photoelectrons are highly energetic, have a long range (up to hundreds of micrometers) in water, and deposit a small fraction of their energy near the nanoparticles. Auger electrons have lower energy and shorter range $(<1 \mu \mathrm{m})$, allowing most of the energy to be deposited around the nanoparticles in nanoscale. ${ }^{25}$ Energy deposition by electrons could result in water hydrolysis and production of ROS (Figure 1A). We suppose that there is a way of improving the production of free hydroxyl radical via chemical reduction by secondary electrons. The presence of reductive drug-modified AuNPs, which would not only produce ROS via water hydrolysis but also undergo drug reduction by secondary electrons generated from the irradiated AuNPs, might also enhance hydroxyl radical production, leading to an increase in cellular radiosensitivity (Figure 1B).

Tirapazamine (TPZ), a hypoxia-selective radiosensitizer, can be reduced by reductase in cells to produce hydroxyl radical. ${ }^{26,27}$ In this study, we designed thioctyl TPZ (TPZs)modified AuNPs (TPZs-AuNPs) by conjugating TPZ moiety on the surface of AuNPs. With the enhanced permeability and retention effect, TPZs-AuNPs offer a high concentration of TPZ in the microenvironment of a tumor. The TPZ moiety would undergo reduction reaction by secondary electrons generated from AuNPs under X-ray irradiation and amplify the production of hydroxyl radicals, providing an effective way of improving the radiation-enhancing effect of AuNPs. After the successful preparation of TPZs-AuNPs, we investigated their radiosensitizing effect on human hepatoma HepG2 cells exposed to X-rays.

\section{Materials and methods}

\section{Reagents and materials}

Chloroauric acid trihydrate $\left(\mathrm{HAuCl}_{4} \cdot 3 \mathrm{H}_{2} \mathrm{O}, 98 \%\right)$ was purchased from Shaanxi Kaida Chemical Engineering Co. (Shaanxi, People's Republic of China). Sodium citrate dihydrate (99\%) was obtained from Shanghai Lingfeng Chemical Reagent Co. (Shanghai, People's Republic of China). 
Thioctic acid (98\%), coumarin-3-carboxylic acid (3-CCA, 97\%), $N$-ethyl- $N^{\prime}$-(3-dimethylaminopropyl) carbodiimide hydrochloride (99\%), and $N$-hydroxybenzotrizole (99\%) were purchased from J\&K Scientific Ltd (Beijing, People's Republic of China). Cyanamide (95\%) and o-nitroaniline (98\%) were purchased from Energy Chemical (Shanghai, People's Republic of China). TPZ was prepared according to the reported procedure. ${ }^{28}$ TPZs was prepared by condensation of thioctic acid with TPZ (Supplementary materials). Polyethylene glycol-capped AuNPs (PEG-AuNPs) were prepared by following the reported procedure. ${ }^{29} \mathrm{TPZs}-\mathrm{AuNPs}$ were prepared by adding a TPZs methanol solution into a PEG-AuNPs aqueous solution.

Human hepatoma HepG2 cells were obtained from the Cell Bank of Shanghai Institutes for Biological Sciences, Chinese Academy of Sciences (Shanghai, People's Republic of China). Rosewell Park Memorial Institute (RPMI)1640 medium, 10\% fetal bovine serum (FBS), trypsin, $100 \mathrm{U} / \mathrm{mL}$ penicillin, and $100 \mu \mathrm{g} / \mathrm{mL}$ streptomycin were purchased from Hyclone Laboratories, Inc. (Logan, UT, USA). 3-(4,5-Dimethyl-2-thiazolyl)-2,5-diphenyl-2- $H$ tetrazolium bromide (MTT) was purchased from Spectrum Chemical Mfg. Corp. (New Brunswick, NJ, USA). All reagents were used as received. Monoclonal antibodies against $\gamma$-H2AX were obtained from Abcam (Cambridge, MA, USA). Rabbit anti-mouse IgG-R antibody was purchased from Santa Cruz Biotechnology Inc. (Dallas, TX, USA). 4',6-Diamidino-2-phenylindole (DAPI) was purchased from Vector Laboratories (Burlingame, CA, USA). 2',7'-Dichlorofluorescein diacetate (DCFH-DA, 98\%) was bought from Biyuntian Biotechnology Institute (Jiangsu, People's Republic of China). Water (18.2 M $\Omega$ ) used in the experiments was obtained from an ultrapure water system (Heal Force Co., Hong Kong, People's Republic of China).

The surface plasemonic resonance of AuNPs was recorded with ultraviolet-visible (UV-vis) spectroscopy (Jasco, Japan) dual-beam spectrophotometer (Model V570) from $200 \mathrm{~nm}$ to $800 \mathrm{~nm}$ with a resolution of $2.0 \mathrm{~nm}$. Transmission electron microscopy (TEM) measurements were performed on a Tecnai TF20 transmission electron microscope (FEI Co., Hillsboro, OR, USA) at $200 \mathrm{kV}$. The concentrations of AuNPs in solution were measured using IRIS ER/S inductively coupled plasma atomic emission spectrometer (ICP-AES; Thermo Jarrell Ash Corp., Franklin, MA, USA) after AuNPs had been dissolved in aqua regia. The zeta potentials of AuNPs were measured using electrophoretic light scattering, and the hydrodynamic diameter of AuNPs was determined by dynamic light scattering on Zetasizer Nano range (Malvern Instruments, Malvern, UK).

The samples were irradiated with X-rays from an RX-650 X-ray source (Faxitron X-ray Co., Tucson, AZ, USA). The dose rate was measured using a Markus ionization chamber (PTW-Freiburg, Freiburg, Germany) connected to a dosimeter (UNIDOS; PTW-Freiburg). The cell number was counted using a particle counter (Z1; Beckman Coulter Inc., Brea, CA, USA). Fluorescence of the irradiated aqueous solutions at $442 \mathrm{~nm}$ was recorded on a microplate reader (Infinite F200/M200; TECAN Co., Männedorf, Switzerland) excited at $395 \mathrm{~nm}$. Fluorescent images of cells were collected on a fluorescence microscope (BX51; Olympus Corporation, Tokyo, Japan).

\section{Cell culture and cell viability assay}

Human hepatoma HepG2 cells were cultured in RPMI-1640 medium supplemented with $10 \% \mathrm{FBS}, 100 \mathrm{U} / \mathrm{mL}$ penicillin, and $100 \mu \mathrm{g} / \mathrm{mL}$ streptomycin. Cultured HepG2 cells were kept at $37^{\circ} \mathrm{C}$ in a $5 \% \mathrm{CO}_{2}$ humidified incubator. To quantify cell uptake of AuNPs, the cells were incubated in flasks with $0-20.0 \mu \mathrm{g} / \mathrm{mL}$ of AuNPs for 24 hours. For X-ray irradiation, the cells were cultured in $35 \mathrm{~mm}$ Petri dishes with/without AuNPs at a concentration of $10.0 \mu \mathrm{g} / \mathrm{mL}$ for 24 hours. Prior to irradiation and uptake measurement, the cells incubated with AuNPs were washed using phosphate-buffered saline (PBS) to remove the noninternalized AuNPs. Fresh medium with FBS and antibiotics was added to the Petri dishes.

To estimate the cytotoxicity of functionalized AuNPs to cells, cell viability was determined with the MTT assay. ${ }^{30}$ Briefly, cells were plated into 96-well tissue culture dishes at a density of $1 \times 10^{4}$ cells $/$ well in $180 \mu \mathrm{L}$ medium. After plating, HepG2 cells were incubated with AuNPs at a concentration of $1.0-10.0 \mu \mathrm{g} / \mathrm{mL}$ for $24-72$ hours, and then $20 \mu \mathrm{L}$ of MTT $(5.0 \mathrm{mg} / \mathrm{mL})$ was added to each well. After incubation at $37^{\circ} \mathrm{C}$ for 4 hours, the supernatants were removed, and formazan crystals were added in $150 \mu \mathrm{L}$ dimethyl sulfoxide (DMSO) solution. The well plates were then read on a microplate reader at $570 \mathrm{~nm}$. The viability change of AuNPs-treated cells was expressed as a percentage compared to the cells without AuNPs treatment, and control cells were considered to have a viability value of $100 \%$. Each experiment was conducted in quintuplicate.

\section{Irradiation}

For solution and cell exposure, samples were set horizontally to be irradiated. The X-ray irradiation was delivered at $50 \mathrm{kVp}$ and $5 \mathrm{~mA}$, and the dose rate was $0.50 \mathrm{~Gy} / \mathrm{min}$. The dose of X-rays delivered to a sample was determined via controlling the irradiation time. For cell exposure, cell 
samples in $35 \mathrm{~mm}$ Petri dishes were irradiated at doses of 1.0, 2.0, 3.0, 4.0, and 6.0 Gy. All irradiations were performed at room temperature.

\section{Measurement of hydroxyl radical and ROS}

Hydroxyl radical production in solution was investigated by using 3-CCA as probe. ${ }^{31}$ Following Cheng et al's procedure, ${ }^{32}$ 3-CCA was dissolved in PBS ( $\mathrm{pH} 7.4)$. The solution was filtered by a $0.22 \mu \mathrm{m}$ membrane filter, and DMSO was added to yield a 3-CCA/DMSO solution, which was then diluted ten times with PBS. PEG-AuNPs and TPZs-AuNPs stock solutions were mixed with the diluted 3-CCA/DMSO solution so as to achieve the same 3-CCA/DMSO molar concentrations and gold concentration $(10.0 \mu \mathrm{g} / \mathrm{mL})$ in samples. An equal volume $(365 \mu \mathrm{L})$ of the samples was added into different wells of 96-well culture plates and kept away from light. Half an hour after irradiation, the AuNPs in the samples were removed by centrifugation to avoid the fluorescence interference of AuNPs. Fluorescence intensities of the samples were measured to determine the produced 7-hydroxyl-coumarin-3-carboxylic acid, which indicates the yield of hydroxyl radicals.

Intracelluar ROS production was measured by using DCFH-DA, a fluorogenic dye for hydroxyl, peroxyl, and other ROS produced within cells. ${ }^{33-35}$ All treatments were carried out in quintuplicate. HepG2 cells were seeded either in $35 \mathrm{~mm}$ Petri dishes for qualitative measurements or in 96-well tissue culture plates for quantitative measurements. All samples were cocultured with $10.0 \mu \mathrm{g} / \mathrm{mL}$ AuNPs for 24 hours. After treatment, cells were incubated with $10.0 \mu \mathrm{M}$ DCFH-DA for 30 minutes followed by irradiation. The cells were then observed under a fluorescence microscope, and all pictures were taken at exactly the same exposure time of 0.2 seconds. For quantitative measurement, the fluorescence intensity at $525 \mathrm{~nm}$ was detected using a fluorescence spectrometer excited at $488 \mathrm{~nm}$, and then normalized by the MTT assay. Each experiment was performed in quintuplicate, and the result is represented as the mean \pm standard deviation (SD).

\section{Clonogenic survival assay}

Cells pretreated with AuNPs for 24 hours were irradiated with X-rays. Immediately after irradiation, the cells were collected by trypsinization, and then were diluted and seeded in $60 \mathrm{~mm}$ Petri dishes at an appropriate density for each treatment. The cells were cultured in RPMI-1640 medium for 15 days, and then fixed with alcohol and stained with crystal violet. Colonies containing $>50$ cells were counted as survivors under a stereomicroscope. Each experiment was performed in quadruplicate, and the result is expressed as the mean $\pm \mathrm{SD}$.

\section{DNA damage measurement}

Cells $\left(1 \times 10^{5}\right)$ were plated on coverslips and allowed 24 hours to attach, and then were pretreated with $10.0 \mu \mathrm{g} / \mathrm{mL}$ AuNPs for 24 hours followed by X-ray irradiation. At different times post-irradiation, the cells were fixed with $4 \%$ paraformaldehyde for 10 minutes. The fixed cells were permeabilized with $0.1 \%$ Triton X-100 and subsequently blocked with $5 \%$ bovine serum albumin at room temperature for 1 hour. The cells were then incubated overnight at $4^{\circ} \mathrm{C}$ with primary monoclonal antibodies against $\gamma$-H2AX (200-fold dilution). After primary antibody incubation, the cells were washed with PBS and incubated with rabbit anti-mouse IgG-R secondary antibody (300-fold dilution) for 1 hour at room temperature. Nuclei were counterstained with mounting medium DAPI at a concentration of $1.5 \mu \mathrm{g} / \mathrm{mL}$. Finally, $\gamma-\mathrm{H} 2 \mathrm{AX}$ foci were detected with a fluorescence microscope.

\section{Cell uptake of nanoparticles}

After cell incubation with AuNPs for 24 hours, the medium was removed. HepG2 cells were washed with PBS and harvested using trypsin. Then, the cell number was counted. Finally, the cell suspension was centrifuged for 20 minutes at $12,000 \mathrm{rpm}$. The pellets were dissolved in aqua regia and diluted with ultrapure water. The concentration of gold was determined by means of ICP-AES. The results presented were normalized by the cell numbers. Data are represented as the mean $\pm \mathrm{SD}$ of the triplicate samples.

\section{Results and discussion}

PEG-AuNPs were reported with excellent colloidal stability in different in vitro environments..$^{21,36,37} \mathrm{We}$ fabricated PEGAuNPs by place-exchange reaction to synthesize aqueous TPZs-AuNPs (Figure 2). Methoxylpolyethyleneglycolthiol was adhered to AuNP surface, and TPZs was anchored on the surface via $\mathrm{Au}-\mathrm{S}$ bonds. As-synthesized TPZs-AuNPs were spherical, relatively monodispersed, and exhibited aqueous colloidal stability for several months. TEM micrographs of the synthesized PEG-AuNPs and TPZs-AuNPs are shown in Figure $3 \mathrm{~A}$ and $\mathrm{B}$. No change in average size was observed after functionalization. The average particle diameter of TPZs-AuNPs was $16.6 \pm 2.1 \mathrm{~nm}$, as derived from the TEM micrographs (Figure 3C). In the UV-vis spectra of TPZs-AuNPs, the characteristic absorption at $526 \mathrm{~nm}$ and a 


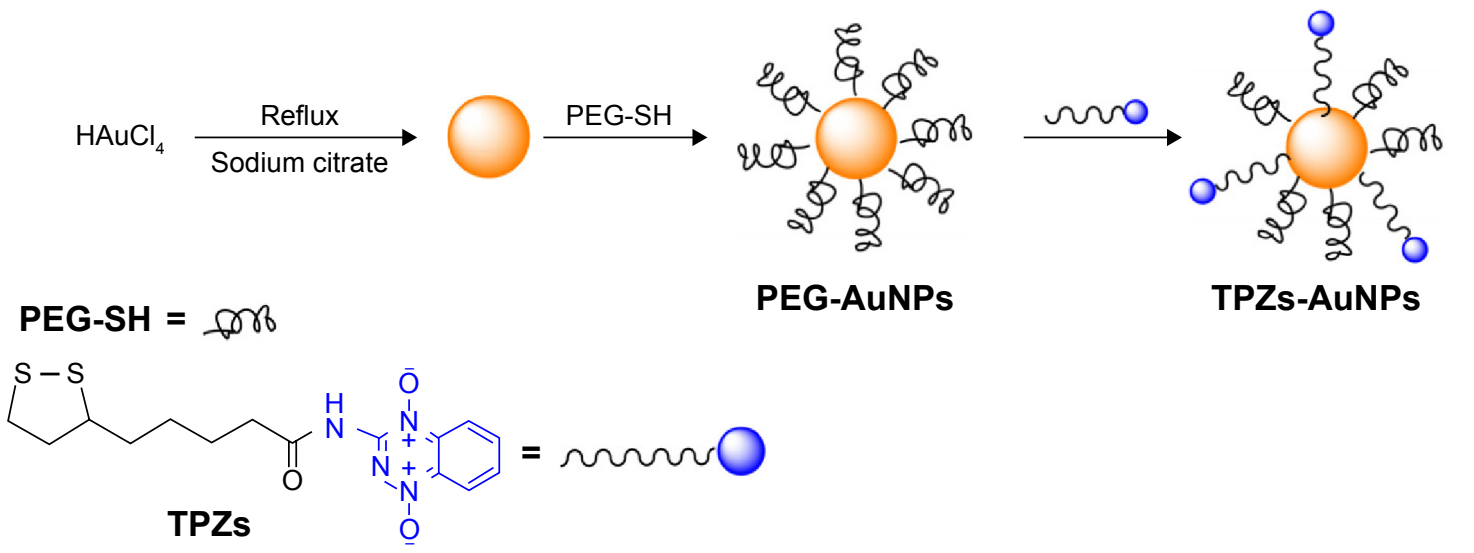

Figure 2 Preparation of TPZs-AuNPs.

Abbreviations: TPZs-AuNPs, thioctyl tirapazamine-modified gold nanoparticles; PEG-AuNPs, polyethylene glycol-capped gold nanoparticles; TPZs, thioctyl tirapazamine.

shoulder band at $264 \mathrm{~nm}$ were in accordance with the surface plasmonic resonance of PEG-AuNPs at $522 \mathrm{~nm}$ and the characteristic band of TPZs at $270 \mathrm{~nm}$, respectively (Figure 3D). ICP-AES was used to measure the Au and S concentrations in PEG-AuNPs and TPZs-AuNPs. In TPZs-AuNPs, the ratio of TPZs to AuNPs was predicted to be 700:1 by ICP-AES, which was close to the ratio of $732: 1$ obtained by UV-vis measurement (Figure S1). Therefore, the concentration of TPZs was $\sim 3.5 \times 10^{-7} \mathrm{M}$ in a $10.0 \mu \mathrm{g} / \mathrm{mL}$ TPZs-AuNPs solution. The modification of nanoparticles always leads


Figure 3 Characterization of gold nanoparticles.

Notes: The TEM image of (A) PEG-AuNPs and (B) TPZs-AuNPs. (C) The size distribution of TPZs-AuNPs. (D) The UV-vis spectra of PEG-AuNPs and TPZs-AuNPs in this study.

Abbreviations: TEM, transmission electron microscopy; PEG-AuNPs, polyethylene glycol-capped gold nanoparticles; TPZs-AuNPs, thioctyl tirapazamine-modified gold nanoparticles; TPZs, thioctyl tirapazamine; UV-vis, ultraviolet-visible. 
to changes in surface chemical activity and hydrodynamic diameter. The zeta potential of $16.6 \mathrm{~nm}$ naked AuNPs was $-45.4 \mathrm{mV}$, which was due to citric acid coating and negative charge on the surface. PEG-SH coating and TPZs conjugation induced the increase of zeta potential to -30.3 and $-13.9 \mathrm{mV}$, respectively. The hydrodynamic diameter of TPZs-AuNPs was $37.8 \mathrm{~nm}$, which was $2.5 \mathrm{~nm}$ less than the size of $40.3 \mathrm{~nm}$ for PEG-AuNPs, as determined by the dynamic light scattering measurements after the conjugation of TPZs on the PEG-AuNPs surface.

With TPZs-AuNPs in hand, we investigated their radiation-enhancing effect through hydroxyl radical production in aqueous solution exposed to X-rays. The radiation enhancements of PEG-AuNPs and TPZs-AuNPs in solutions were evaluated by hydroxyl radical production using 3-CCA as probe following the procedure presented by Cheng et al. ${ }^{32}$ The fluorescence intensity of irradiated solution increased along with the radiation dose (Figure S2). The radiation enhancement ratio could be calculated using the equation $E_{\mathrm{r}}=F_{\mathrm{i}} / F_{0}$, where $E_{\mathrm{r}}, F_{\mathrm{i}}$, and $F_{0}$ stand for enhancement ratio, fluorescence intensity of the irradiated solution with or without AuNPs, and fluorescence intensity of the nonirradiated 3-CCA solution without AuNPs (control), respectively. The dependence of the radiation enhancement ratios of PEGAuNPs and TPZs-AuNPs on the radiation dose is shown in Figure 4A. Clearly, the fluorescence intensities did not change when PEG-AuNPs and TPZs-AuNPs were added to 3-CCA solutions. When the solutions were irradiated with $\mathrm{X}$-rays of $2.0 \mathrm{~Gy}$, the enhancement ratio increased to 1.29 for PEG-AuNPs, which was slightly higher than 1.27 for
X-rays alone but was 21\% lower than 1.56 for TPZs-AuNPs. The same phenomenon was observed when the exposure dose increased to 4.0 Gy. TPZs-AuNPs showed an enhancement ratio of 2.56 in terms of hydroxyl radical production, which was $23.7 \%$ higher than 2.07 for PEG-AuNPs. The presence of $50 \mathrm{mM}$ DMSO in solution resulted in hydroxyl radical quenching, and thus the sharp decrease in enhancement ratio to the control level. These results demonstrated that TPZs-AuNPs presented 20\% more radiation enhancement in terms of hydroxyl radical production in aqueous solution induced by X-rays than PEG-AuNPs at the same gold concentration.

Since TPZ moiety might also induce hydroxyl radical production under X-ray irradiation, we investigated the hydroxyl radical production of TPZ solution exposed to X-rays. No enhancement was observed even up to the concentration of $2.5 \mu \mathrm{M}$ (Figure S3), which was approximately sixfold higher than the TPZ moiety concentration in $10.0 \mu \mathrm{g} / \mathrm{mL}$ TPZsAuNPs solution. Furthermore, we studied the cytotoxicity of TPZ and TPZs (Figure S4A and B) to HepG2 cells. After coculturing with $0-1.0 \mu \mathrm{M}$ TPZ and TPZs for 24 hours, no apparent decrease in cell viability was observed. When the coculture time was prolonged to 48 and 72 hours, obvious cell viability inhibition of TPZ and TPZs was observed. This might be due to the accumulation of TPZ moiety in cells with increasing the coculture time, leading to endogenous hydroxyl radical improvement and subsequently cell apoptosis. Besides free TPZs moiety, we further studied the cytotoxicity of TPZs-AuNPs as well as PEG-AuNPs to HepG2 cells. As shown in Figure 4B, the viability of HepG2 cells
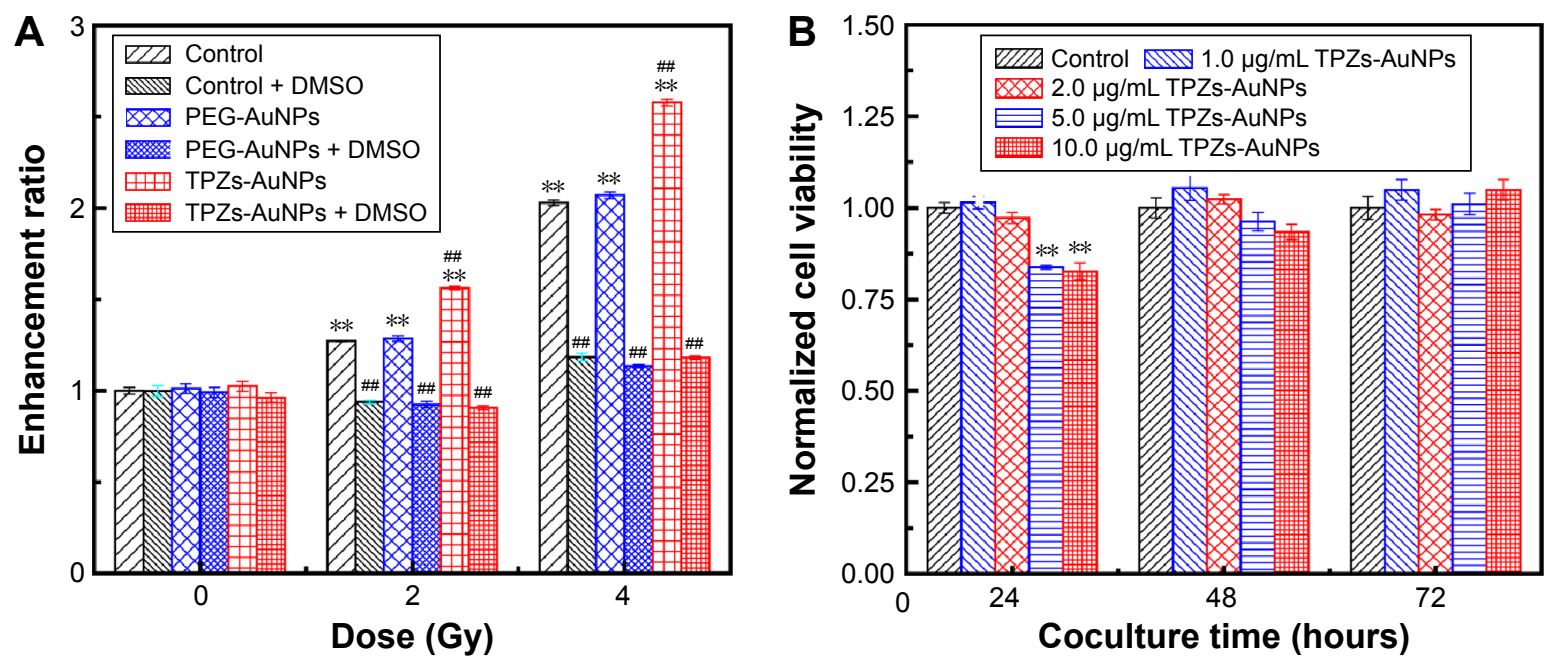

Figure 4 Radiation enhancement in solution and cell viability of gold nanoparticles.

Notes: (A) The radiation enhancement ratio of PEG-AuNPs and TPZs-AuNPs concerning hydroxyl radical production in solutions exposed to X-rays (50 kVP) at the gold concentration of $10.0 \mu \mathrm{g} / \mathrm{mL}$. (B) The normalized viability of HepG2 cells cocultured with TPZs-AuNPs at various concentrations for 24,48 , and 72 hours. **P $<0.0 \mathrm{I}$ versus control group without irradiation and ${ }^{\#}<0.01$ versus control group with $X$-ray alone, determined by the two-tailed Student's $t$-test.

Abbreviations: PEG-AuNPs, polyethylene glycol-capped gold nanoparticles; TPZs-AuNPs, thioctyl tirapazamine-modified gold nanoparticles; DMSO, dimethyl sulfoxide. 
did not decrease when cocultured with 0-2.0 $\mu \mathrm{g} / \mathrm{mL}$ TPZsAuNPs for 24 hours. The cell viability reduced to $\sim 83 \%$ after coculturing with $10.0 \mu \mathrm{g} / \mathrm{mL}$ TPZs-AuNPs for 24 hours but recovered to $93 \%$ and $100 \%$ when the coculture time was prolonged to 48 and 72 hours, respectively. In addition, the viability of HepG 2 cells decreased by $2 \%-8 \%$ after coculturing with $0-10.0 \mu \mathrm{g} / \mathrm{mL}$ PEG-AuNPs for 24 hours. Further slight decrement in cell viability was observed for 48- and 72-hour coculture times (Figure S4C). Clearly, PEG-AuNPs and TPZs-AuNPs did not affect the viability of HepG2 cells significantly. When TPZ moiety was conjugated to the surface of AuNPs, the cytotoxicity of TPZ moiety was reduced.

The low cytotoxicity of TPZs-AuNPs and good stability encouraged us to investigate their intracellular ROS enhancement. ROS produced in normal cellular environments are essential for life and become harmful when overproduced. The intracellular ROS were visualized via DCFH-DA probes for HepG2 cells with or without $10.0 \mu \mathrm{g} / \mathrm{mL}$ AuNPs as shown in Figure 5A. Without X-ray irradiation, little visible fluorescence was observed after cells were treated with AuNPs for
20 minutes. After irradiation, a strong fluorescence was emitted by the AuNPs-treated cells. The enhancement ratio of ROS upon irradiation is shown in Figure 5B. Without irradiation, the ROS production in the presence of TPZs-AuNPs was $\sim 12 \%$ higher than the control, which was consistent with the cytotoxicity result. No significant enhancement of ROS production was observed in HepG2 cells with PEG-AuNPs under X-ray irradiation compared to the control. The presence of TPZs-AuNPs led to $\sim 23 \%$ higher fluorescence intensity than PEG-AuNPs at the dose of $2.0 \mathrm{~Gy}$. When the radiation dose reached $4.0 \mathrm{~Gy}$, the intracellular ROS yield increased to 2.6-fold in the presence of PEG-AuNPs, which was only $4 \%$ higher than the control without AuNPs. In contrast, the yield increased to 3.1-fold in the presence of TPZs-AuNPs, a 19.2\% increment in ROS production than PEG-AuNPs. These results demonstrated that the presence of TPZs-AuNPs contributed to $\sim 20 \%$ increment in ROS production in cells compared with PEG-AuNPs. This is in accordance with the result of hydroxyl radical production, indicating that the intracellular ROS increment mainly came from the increase of hydroxyl radical yield.

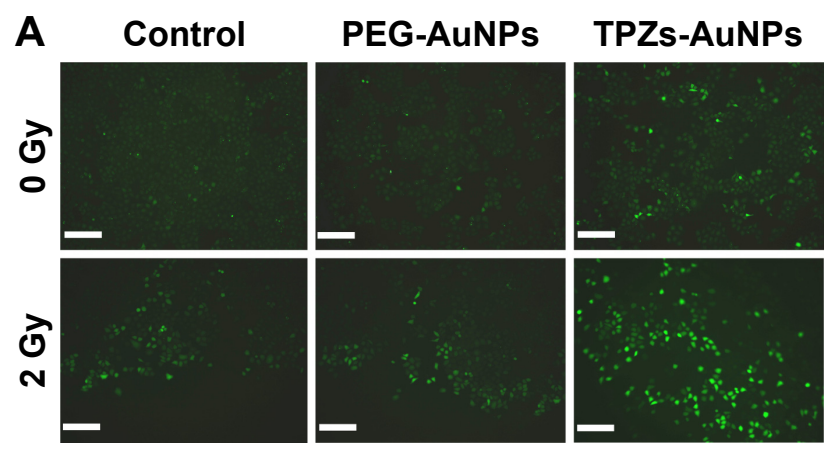

B

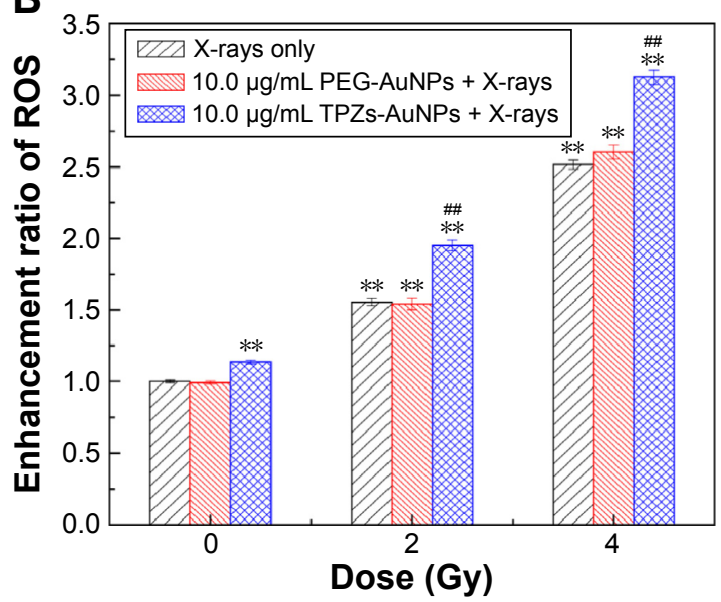

C

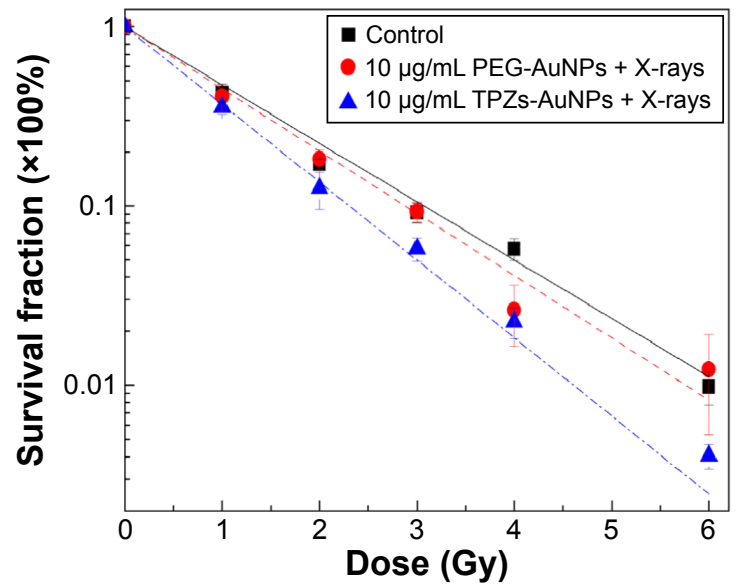

Figure 5 Radiation enhancement in cells.

Notes: (A) The fluorescence images of ROS with DCFH-DA in HepG2 cells after X-ray irradiation in the presence of PEG-AuNPs and TPZs-AuNPs. All scale bars represent $200 \mu \mathrm{m}$. (B) The enhancement ratio of ROS in HepG2 cells after X-ray irradiation in the presence of PEG-AuNPs and TPZs-AuNPs compared to control. (C) The survival curves of HepG2 cells in the presence of PEG-AuNPs and TPZs-AuNPs after exposure to $50 \mathrm{kV}$ P $X$-rays. $* * P<0.01$ versus control group and $\# P<0.01$ versus $X$-rays alone, determined by the two-tailed Student's $t$-test.

Abbreviations: ROS, reactive oxygen species; DCFH-DA, 2',7'-dichlorofluorescein diacetate; PEG-AuNPs, polyethylene glycol-capped gold nanoparticles; TPZs-AuNPs, thioctyl tirapazamine-modified gold nanoparticles. 
The satisfactory result in ROS enhancement in HepG2 cells induced by X-rays in combination with TPZs-AuNPs prompted us to investigate the subsequent cell survival effect under X-ray irradiation combined with AuNPs. To test the role of TPZ-AuNPs in radiation-induced cytotoxicity enhancement, cell clonogenic survival experiments were carried out. The survival curves of HepG2 cells in the presence of AuNPs irradiated with X-rays are displayed in Figure 5C. Clearly, the cell survival fraction decreased exponentially with increase in the radiation dose. The addition of $10.0 \mu \mathrm{g} / \mathrm{mL}$ TPZs-AuNPs led to a sharper decrease in survival fraction than PEG-AuNPs along with a decrease in the radiation dose. The doses of X-rays required to obtain $10 \%$ cell survival fraction for HepG2 cells were 3.10, 2.92, and 2.32 Gy for the control without AuNPs, PEG-AuNPs, and TPZs-AuNPs, respectively. The sensitizer enhancement ratios of PEG-AuNPs and TPZ-AuNPs were 1.05 and 1.25 at the concentration of $10.0 \mu \mathrm{g} / \mathrm{mL}$, respectively (Table 1). Compared to PEG-AuNPs, TPZs-AuNPs showed an increase of $19 \%$ in sensitizer enhancement ratio at $10 \%$ survival level for HepG2 cells under X-ray irradiation. This result is in accordance with the enhancement in hydroxyl radical production and intracellular ROS. As mentioned earlier, the addition of DMSO led to the hydroxyl radical quenching. Consequently, we deduced that the survival fraction decrease of HepG2 cells with TPZs-AuNPs under X-ray irradiation was mainly due to the increase in hydroxyl radical production. Therefore, the TPZ moiety on AuNPs surface contributed to the increase in ROS production and ultimately decrease in cell survival.

Cell death or apoptosis induced by ionizing radiations might be mainly attributed to the nucleus damages such as base damages, DNA-protein cross-links, and DNA doublestrand breaks (DSBs). ${ }^{38}$ DNA DSBs in HepG 2 cells exposed to X-rays in the presence of TPZs-AuNPs and PEG-AuNPs were then investigated to clarify whether the increased cell lethality was derived from nucleus or cytoplasm damages.

Table I Required dose for 10\% survival level and sensitizer enhancement ratio at $10 \%$ survival level for HepG2 cells cocultured with PEG-AuNPs and TPZ-AuNPs at a concentration of $10.0 \mu \mathrm{g} / \mathrm{mL}$

\begin{tabular}{lllll}
\hline Items & & Control & PEG-AuNPs & TPZs-AuNPs \\
\hline SF =10\% & $\begin{array}{l}\text { Dose required for } \\
\text { X-rays (Gy) }\end{array}$ & 3.10 & 2.92 & 2.32 \\
& $\begin{array}{l}\text { Sensitizer } \\
\text { enhancement ratio }\end{array}$ & 1.00 & 1.05 & 1.25 \\
\hline
\end{tabular}

Abbreviations: PEG-AuNPs, polyethylene glycol-capped gold nanoparticles; TPZs-AuNPs, thioctyl tirapazamine-modified gold nanoparticles; SF, survival fraction.
$\gamma$-H2AX on Ser139 is one of the key events of DNA damage response and considered to be a marker of DSBs. ${ }^{39}$ Figure $6 \mathrm{~A}$ shows the results of $\gamma-\mathrm{H} 2 \mathrm{AX}$ foci detection acquired in this study for HepG2 cells in the presence of PEG-AuNPs and TPZs-AuNPs. The number of $\gamma$-H2AX foci in HepG2 cells was $3.2 \pm 1.1$, while it slightly increased to $4.1 \pm 1.8$ and 5.1 \pm 1.5 when cells were pretreated with PEG-AuNPs and TPZs-AuNPs for 24 hours, respectively. When HepG2 cells were irradiated with X-rays of $2.0 \mathrm{~Gy}$, the number of $\gamma$-H2AX foci significantly increased to $22.4 \pm 5$.3. No obvious difference in the number of $\gamma-\mathrm{H} 2 \mathrm{AX}$ foci in the cells with or without AuNPs was observed. The number of $\gamma$-H2AX foci slightly increased by 1.7 and 2.4 for cells with PEG-AuNPs and TPZs-AuNPs at 12 hours post-irradiation, respectively, suggesting that DNA damage was mainly exacerbated by $\mathrm{X}$-rays and slightly improved by addition of PEG-AuNPs and TPZs-AuNPs. No obvious difference in DNA DSBs reflected by the $\gamma$-H2AX foci was found for HepG2 cells with TPZsAuNPs or PEG-AuNPs under X-ray irradiation. Probably, the difference in the damages between HepG2 cells with TPZs-AuNPs and PEG-AuNPs induced by X-rays mainly came from the damages in cytoplasm instead of nucleus. This is also coincident with the accumulation of AuNPs in cytoplasm observed in our previous study. ${ }^{23}$

The conjugation of TPZ moiety to PEG-AuNPs surface resulted in changes in particle size and zeta potential, thus possibly influencing the cell uptake. The concentration of AuNPs, especially cell uptake of AuNPs, is the key factor for the enhancement of radiation effect. As shown in Figure 6B, the cell uptake increased with increasing gold concentration in the range of $0-20.0 \mu \mathrm{g} / \mathrm{mL}$. The cell uptake for TPZs-AuNPs at $10.0 \mu \mathrm{g} / \mathrm{mL}$ concentration was $17.32 \mathrm{fg} / \mathrm{cell}$, while it was only $8.08 \mathrm{fg} /$ cell for PEG-AuNPs. The HepG2 cell uptake of TPZs-AuNPs was approximately tenfold lower than HeLa cell uptake of citrate-capped AuNPs shown in our previous study. ${ }^{23}$ The experiments were conducted at the same coculture concentration of AuNPs, but the cell uptake of TPZsAuNPs was twice more than that of PEG-AuNPs. Whether the radiation enhancement of TPZs-AuNPs is derived from the higher cell uptake of AuNPs is not known.

We then investigated the enhancement in intracellular ROS production for HepG2 cells cocultured with $5.0 \mu \mathrm{g} / \mathrm{mL}$ TPZs-AuNPs and $20.0 \mu \mathrm{g} / \mathrm{mL}$ PEG-AuNPs under X-ray irradiation (Figure S5). The coculture concentrations of these two AuNPs corresponded to 14.75 and $13.43 \mathrm{fg} / \mathrm{cell}$ in terms of gold concentration in HepG2 cells, respectively, that is, almost the same gold concentration in cells. The enhancement ratio of ROS production was $\sim 1.24$ for TPZs-AuNPs without 

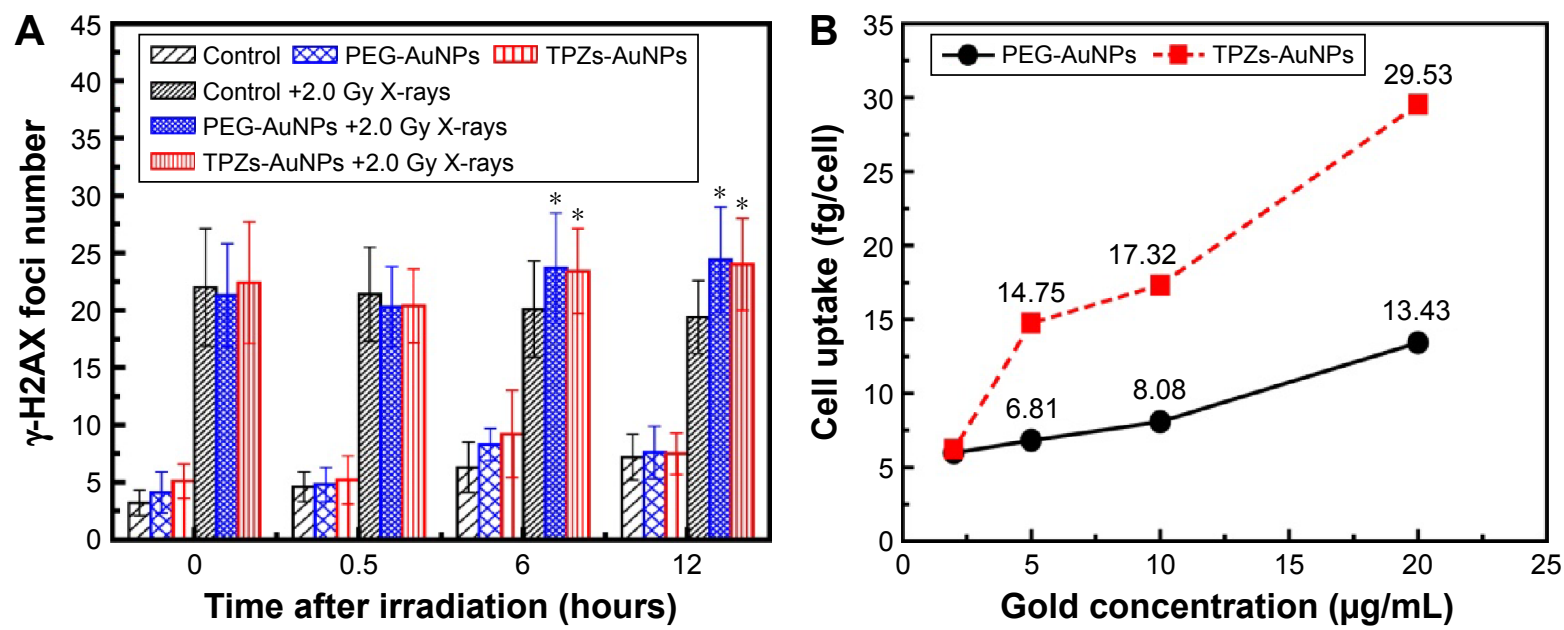

Figure 6 The dependence of $\gamma-\mathrm{H} 2 \mathrm{AX}$ foci and cell uptake of gold nanoparticles.

Notes: (A) The numbers of $\gamma$ - $\mathrm{H} 2 \mathrm{AX}$ foci in AuNPs-pretreated HepG2 cells under X-ray irradiation at different times post-irradiation. (B) The dependence of uptake of PEG-AuNPs and TPZs-AuNPs by HepG2 cells on coculture concentration. ${ }^{*} P<0.05$ versus control group, determined by the two-tailed Student's $t$-test.

Abbreviations: AuNPs, gold nanoparticles; PEG-AuNPs, polyethylene glycol-capped gold nanoparticles; TPZs-AuNPs, thioctyl tirapazamine-modified gold nanoparticles.

irradiation, which was $24 \%$ higher than that in cells without TPZs-AuNPs. This might be due to the endogenous hydroxyl radical production elicited by the accumulated TPZs-AuNPs. When irradiated with X-rays at $2.0 \mathrm{~Gy}$, the radiation enhancement ratios were $1.77,1.80$, and 2.43 for the control, PEGAuNPs-pretreated cells, and TPZs-AuNPs-pretreated cells, respectively. Therefore, the addition of PEG-AuNPs and TPZ-AuNPs led to $1.7 \%$ and $37.3 \%$ increments in radiation enhancement ratio, respectively. When the radiation dose increased to $4.0 \mathrm{~Gy}$, TPZ-AuNPs also exhibited $38 \%$ increment in radiation enhancement ratio. These results further proved that the conjugation of TPZ moiety on the surface of PEG-AuNPs elicited a greater radiation enhancement than PEG-AuNPs alone under X-ray irradiation.

The radiosensitizing effect of AuNPs has been shown to depend very strongly on the concentration, size, shape, and coating of AuNPs. ${ }^{40}$ In our cell radiobiological experiment, $10.0 \mu \mathrm{g} / \mathrm{mL}(\sim 50 \mu \mathrm{M}$ gold concentration) TPZs-AuNPs were used, which was one-tenth of the concentration of PEG-AuNPs used by Liu et al, where $10 \%$ radiation enhancement was obtained for $150 \mathrm{kVp} \mathrm{X}$-rays. ${ }^{36}$ As far as the gold concentration in a cell is concerned, it was $17.32 \mathrm{fg} /$ cell for the coculture concentration of $10.0 \mu \mathrm{g} / \mathrm{mL}$, that is, $17.32 \mathrm{ppm}$ (the weight of $10^{9}$ cells is $\sim 1.0 \mathrm{~g}$ ) in HepG2 cells. As proposed, the accumulated TPZs-AuNPs in endosome/lysosome provided a relatively high concentration of AuNPs and TPZs. On one hand, accumulated AuNPs and TPZs might absorb X-rays to directly produce ROS. On the other hand, plenty of secondary electrons, generated from the irradiated AuNPs, could be captured by TPZ moiety on the AuNPs surface, undergoing a reductive reaction to produce hydroxyl radicals (Figure 7). ${ }^{27}$ It could be treated as an intramolecular electron transfer system, which was much more

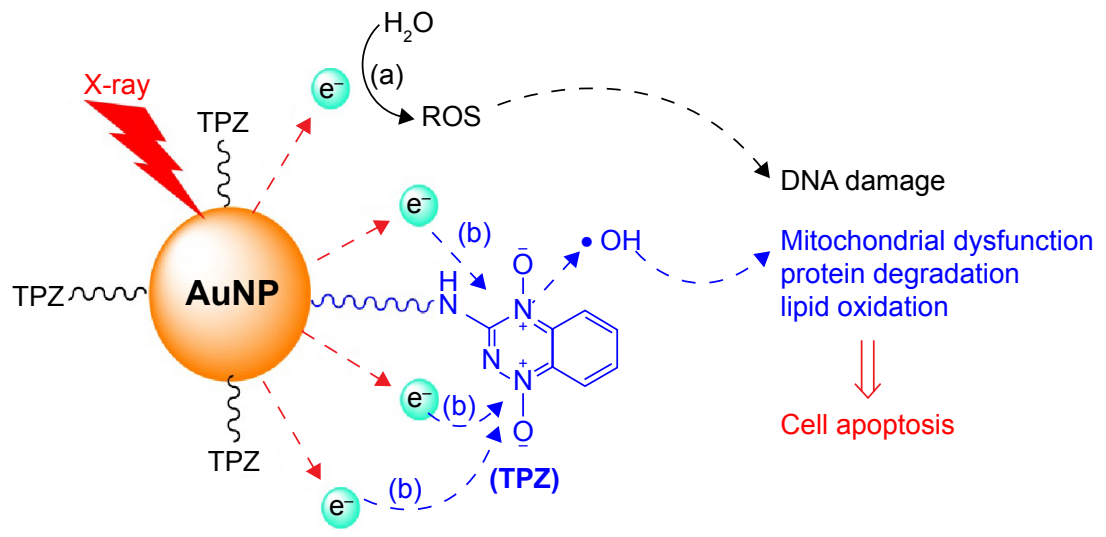

Figure 7 The radiation enhancement mechanism of TPZs-AuNPs proposed in this study.

Abbreviations: TPZ, tirapazamine; AuNP, gold nanoparticle; ROS, reative oxygen species; TPZs-AuNPs, thioctyl tirapazamine-modified gold nanoparticles. 
efficient than intermolecular electron transfer. Therefore, the synergetic effect between TPZ moiety and AuNPs contributed to the significant radiation enhancement, although a very low loading of TPZs-AuNPs was used. Further study on the protein expression and signal transduction induced by TPZs-AuNPs is needed to disclose the molecular mechanisms underlying the enhanced cell-killing effect. Additionally, because TPZ is a specific drug for hypoxia cells, the radiosentizing effect of TPZs-AuNPs on cells under hypoxia condition as well as in vivo will be investigated in our future study.

\section{Conclusion}

We successfully fabricated AuNPs with TPZ moiety by conjugating TPZs on their surface using place-exchange reaction. Our study showed that HepG2 cell lethality induced by X-rays could be enhanced $>20 \%$ in vitro in the presence of TPZs-AuNPs compared to PEG-AuNPs at almost the same gold concentration. The ROS measurement proved that the reduction of TPZ could be chemically improved by secondary electrons from AuNPs under X-ray irradiation. The synergetic effect between TPZ moiety and AuNPs led to the significant radiation enhancement of TPZs-AuNPs. The improvement which we achieved in this study using drug-modified AuNPs with low gold loading suggests that this methodology is potentially useful for designing more efficient radiation sensitizers for clinical use in the future.

\section{Acknowledgments}

This work was jointly supported by the Key Project of National Natural Science Foundation of China (Grant No U1232207), the National Key Technology Support Program (Grant No 2015BA101B11), National key Research and Development Program (Grant No 2016YFC0904602) of the Ministry of Science and Technology of China, and the National Natural Science Foundation of China (Grant No 11075191, 11205217, and 11475231).

\section{Disclosure}

The authors report no conflicts of interest in this work.

\section{References}

1. Ferlay J, Soerjomataram I, Dikshit R, et al. Cancer incidence and mortality worldwide: sources, methods and major patterns in GLOBOCAN 2012. Int J Cancer. 2015;136(5):E359-E386.

2. Jemal A, Bray F, Center MM, et al. Global cancer statistics. CA Cancer J Clin. 2011;61(2):69-90.

3. Wardman P. Chemical radiosensitizers for use in radiotherapy. Clin Oncol. 2007; 19:397-417.

4. Jain M, Venkatraman G, Batra S. Cell-penetrating peptides and antibodies: a new direction for optimizing radioimmunotherapy. Eur $J$ Nucl Med Mol Imaging. 2007;34(7):973-977.
5. Liu CJ, Wang CH, Chien CC, et al. Enhanced $\mathrm{x}$-ray irradiation-induced cancer cell damage by gold nanoparticles treated by a new synthesis method of polyethylene glycol modification. Nanotechnology. 2008; 19(29):295104.

6. Tofilon PJ, Camphausen K. Molecular targets for tumor radiosensitization. Chem Rev. 2009;109(7):2974-2988.

7. Jain S, Coulter JA, Hounsell AR, et al. Cell-specific radiosensitization by gold nanoparticles at megavoltage radiation energies. Int J Radiat Oncol Biol Phys. 2011;79(2):531-539.

8. Kobayashi K, Usami N, Porcel E, et al. Enhancement of radiation effect by heavy elements. Mutat Res. 2010;704(1-3):123-131.

9. Matsudaira H, Ueno AM, Furuno I. Iodine contrast-medium sensitizes cultured mammalian-cells to X-rays but not to gamma-rays. Radiat Res. 1980;84(1):144-148.

10. Chen PC, Mwakwari SC, Oyelere AK. Gold nanoparticles: from nanomedicine to nanosensing. Nanotechnol Sci Appl. 2008;1:45-66.

11. Yu MK, Park J, Jon S. Targeting strategies for multifunctional nanoparticles in cancer imaging and therapy. Theranostics. 2012;2(1): 3-44.

12. Jelveh S, Chithrani DB. Gold nanostructures as a platform for combinational therapy in future cancer therapeutics. Cancers. 2011;3(1): 1081-1110.

13. Hainfeld JF, Slatkin DN, Smilowitz HM. The use of gold nanoparticles to enhance radiotherapy in mice. Phys Med Biol. 2004;49(18): N309-N315.

14. Hainfeld JF, Slatkin DN, Focella TM, et al. Gold nanoparticles: a new X-ray contrast agent. Br J Radiol. 2006;79(939):248-253.

15. Kong T, Zeng J, Wang XP, et al. Enhancement of radiation cytotoxicity in breast-cancer cells by localized attachment of gold nanoparticles. Small. 2008;4(9):1537-1543.

16. McMahon SJ, Hyland WB, Muir MF, et al. Nanodosimetric effects of gold nanoparticles in megavoltage radiation therapy. Radiother Oncol. 2011;100(3):412-416.

17. Porcel E, Liehn S, Remita H, et al. Platinum nanoparticles: a promising material for future cancer therapy? Nanotechnology. 2010;21(8): 085103.

18. Alqathami M, Blencowe A, Yeo UJ, et al. Enhancement of radiation effects by bismuth oxide nanoparticles for kilovoltage x-ray beams: a dosimetric study using a novel multi-compartment 3D radiochromic dosimeter. J Phys Conf Ser. 2013;444:012025.

19. Luo Y, Hossain M, Wang CM, et al. Targeted nanoparticles for enhanced $\mathrm{X}$-ray radiation killing of multidrug-resistant bacteria. Nanoscale. 2013;5(2):687-694.

20. Jain S, Hirst DG, O'Sullivan JM. Gold nanoparticles as novel agents for cancer therapy. Br J Radiol. 2012;85(1010):101-113.

21. Zhang XD, Wu D, Shen X, et al. Size-dependent radiosensitization of PEG-coated gold nanoparticles for cancer radiation therapy. Biomaterials. 2012;33(27):6408-6419.

22. Brun E, Sanche L, Sicard-Roselli C. Parameters governing gold nanoparticle X-ray radiosensitization of DNA in solution. Colloids Surf B Biointerfaces. 2009;72(1):128-134.

23. Liu Y, Liu X, Jin X, et al. The dependence of radiation enhancement effect on the concentration of gold nanoparticles exposed to low- and high-LET radiations. Phys Med. 2015;31(3):210-218.

24. Liu Y, Liu X, Jin X, et al. The radiation enhancement of 15-nm citratecapped gold nanoparticles exposed to $70 \mathrm{keV} / \mu \mathrm{m}$ carbon ions. J Nanosci Nanotechnol. 2016;16(3):2365-2370.

25. Hossain M, Su M. Nanoparticle location and material-dependent dose enhancement in X-ray radiation therapy. J Phys Chem C. 2012; 116(43):23047-23052.

26. Daniels JS, Gates KS. DNA cleavage by the antitumor agent 3-amino1,2,4-benzotriazine 1,4-dioxide (SR4233): evidence for involvement of hydroxyl radical. J Am Chem Soc. 1996;118(14):3380-3385.

27. Junnotula V, Sarkar U, Sinha S, et al. Initiation of DNA strand cleavage by 1,2,4-benzotriazine 1,4-dioxide antitumor agents: mechanistic insight from studies of 3-methyl-1,2,4-benzotriazine 1,4-dioxide. $\mathrm{J} \mathrm{Am}$ Chem Soc. 2009;131(3):1015-1024. 
28. Hay MP, Gamage SA, Kovacs MS, et al. Structure-activity relationships of 1,2,4-benzotriazine 1,4-dioxides as hypoxia-selective analogues of tirapazamine. J Med Chem. 2003;46(1):169-182.

29. Frens G. Controlled nucleation for regulation of particle-size in monodisperse gold suspensions. Nat Phys Sci. 1973;241(105):20-22.

30. Sobottka SB, Berger MR. Assessment of antineoplastic agents by MTT assay - partial underestimation of antiproliferative properties. Cancer Chemother Pharmacol. 1992;30(5):385-393.

31. Gomes A, Fernandes E, Lima JL. Fluorescence probes used for detection of reactive oxygen species. J Biochem Biophys Methods. 2005; 65(2-3):45-80.

32. Cheng NN, Starkewolf Z, Davidson RA, et al. Chemical enhancement by nanomaterials under X-ray irradiation. J Am Chem Soc. 2012;134: 1950-1953.

33. Wang H, Joseph JA. Quantifying cellular oxidative stress by dichlorofluorescein assay using microplate reader. Free Radic Biol Med. 1999; 27(5-6):612-616.

34. Aruoma OI, Grootveld M, Bahorun T. Free radicals in biology and medicine: from inflammation to biotechnology. Biofactors. 2006; $27(1-4): 1-3$.
35. Degli EM. Measuring mitochondrial reactive oxygen species. Methods. 2002;26(4):335-340.

36. Liu C-J, Wang C-H, Chen S-T, et al. Enhancement of cell radiation sensitivity by pegylated gold nanoparticles. Phys Med Biol. 2010;55(4): 931-945.

37. Zhang G, Yang Z, Lu W, et al. Influence of anchoring ligands and particle size on the colloidal stability and in vivo biodistribution of polyethylene glycol-coated gold nanoparticles in tumor-xenografted mice. Biomaterials. 2009;30(10):1928-1936.

38. Pouget JP, Mather SJ. General aspects of the cellular response to lowand high-LET radiation. Eur J Nucl Med. 2001;28(4):541-561.

39. Vandersickel V, Depuydt J, Bockstael BV, et al. Early increase of radiation-induced gamma $\mathrm{H} 2 \mathrm{AX}$ foci in a human $\mathrm{Ku} 70 / 80$ knockdown cell line characterized by an enhanced radiosensitivity. J Radiat Res. 2010;51(6):633-641.

40. Butterworth KT, McMahon SJ, Currell FJ, et al. Physical basis and biological mechanisms of gold nanoparticle radiosensitization. Nanoscale. 2012;4(16):4830-4838. 


\section{Supplementary materials}

The preparation process of thioctyl

tirapazamine

The synthesis of 3-amine-I,2,4-benzotriazole-I-oxide 2-Nitroaniline $(4.3 \mathrm{mmol})$ and cyanamide $(22 \mathrm{mmol})$ were melted together at $100^{\circ} \mathrm{C}$, and then cooled to $50^{\circ} \mathrm{C}$. Concentrated $\mathrm{HCl}(5 \mathrm{~mL})$ was added carefully. The mixture was stirred until the exotherm subsided and then stirred at $100^{\circ} \mathrm{C}$ for 2 hours. Cyanamide $(22 \mathrm{mmol})$ was added, and the mixture was stirred at $100^{\circ} \mathrm{C}$ for 4 hours. The mixture was cooled to $20^{\circ} \mathrm{C}$ and made strongly basic with $7.5 \mathrm{M} \mathrm{NaOH}$ solution $(50 \mathrm{~mL})$, and heated at $100^{\circ} \mathrm{C}$ for 1 hour. Then, the mixture was cooled to $20^{\circ} \mathrm{C}$ and diluted with water $(100 \mathrm{~mL})$. The precipitate was filtered, washed with water $(2 \times 10 \mathrm{~mL})$ and ether $(2 \times 10 \mathrm{~mL})$, and dried to obtain the corresponding 3-amine-1,2,4-benzotriazole-1-oxide.

The synthesis of 3-amine-I,2,4-benzotriazole-I,4dioxide (tirapazamine)

Hydrogen peroxide $(30 \%, 12 \mathrm{~mL})$ was added dropwise to a suspension of 3-amine-1,2,4-benzotriazole-1-oxide $(2.60 \mathrm{mmol})$ in $\mathrm{HOAc}(25 \mathrm{~mL})$, and the suspension was stirred at $50^{\circ} \mathrm{C}$ for 4 hours. The solution was diluted with water $(100 \mathrm{~mL})$ and carefully neutralized with solid $\mathrm{NaHCO}_{3}$. The solution was extracted with chloroform $\left(\mathrm{CHCl}_{3}\right)(5 \times 50 \mathrm{~mL})$, the combined organic extracts were dried, and the solvent was evaporated. The residue was chromatographed, by eluting with a gradient $(0 \%-5 \%)$ of $\mathrm{MeOH} / \mathrm{CHCl}_{3}$, to obtain the corresponding 1,2,4-benzotriazin-3-amine-1,4-dioxide (tirapazamine, TPZ) (melting point $\left.228^{\circ} \mathrm{C}-230^{\circ} \mathrm{C}\right) .{ }^{1} \mathrm{H} \mathrm{NMR}\left(400 \mathrm{MHz}, \mathrm{CDCl}_{3}\right)$ $\delta 8.57\left(\mathrm{dd}, J_{1}=12.8 \mathrm{~Hz}, J_{2}=8.6 \mathrm{~Hz}, 2 H\right), 8.14-8.03(\mathrm{~m}, 1 H)$, $7.97(\mathrm{~m}, 1 H), 4.08(\mathrm{~s}, 2 H)$. MS $(\mathrm{m} / \mathrm{z}) 178.05\left(\mathrm{M}^{+}, 100 \%\right)$.

\section{The synthesis of thioctyl tirapazamine}

Thioctic acid $(0.412 \mathrm{~g}, 2 \mathrm{mmol})$ was dissolved in dichloromethane $(20 \mathrm{~mL})$, followed by addition of triethylamine (0.6 mL), and then $N$-ethyl- $N^{\prime}$-(3-dimethylaminopropyl) carbodiimide hydrochloride $(0.460 \mathrm{~g}, 2.4 \mathrm{mmol})$ and $N$-hydroxybenzotrizole $(0.324 \mathrm{~g}, 1.2 \mathrm{mmol})$ were added. The mixture was stirred at room temperature for 1 hour. TPZ (0.356 g, $2 \mathrm{mmol}$ ) was added. The resulting mixture was stood overnight. After treatment, the residue was purified by silicon column chromatography to give thioctyl tirapazamine (TPZs; $0.439 \mathrm{~g}, 60 \%$ yield). ${ }^{1} \mathrm{H}$ NMR (400 MHz, $\left.\mathrm{CDCl}_{3}\right) \delta 9.08(\mathrm{~s}, 1 H), 8.57$ (d, $J=8.4 \mathrm{~Hz}, 1 H$ ), $8.54(\mathrm{~d}, J=8.4 \mathrm{~Hz}, 1 H), 8.10$ (dd, $J_{1}=8.4 \mathrm{~Hz}, J_{2}=7.2 \mathrm{~Hz}, 1 H$ ), $7.97\left(\mathrm{dd}, J_{1}=8.4 \mathrm{~Hz}, J_{2}=7.2 \mathrm{~Hz}, 1 H\right), 3.61(\mathrm{~m}, 1 H), 3.18$ (m, 2H), 2.49 (m, 1H), 2.41 (t, J=6.8 Hz, 2H), 1.95 (m, 1H), $1.68-1.85(\mathrm{~m}, 4 H), 1.658(\mathrm{~m}, 2 H)$. HR-MS $(\mathrm{M}+\mathrm{H})^{+} \mathrm{m} / z$ : 366.0820, found: 366.0807 .

\section{The measurement of TPZs number in TPZs-modified AuNPs using UV-vis spectroscopy}

A standard curve of TPZs

TPZs $(5.0 \mathrm{mg})$ was dissolved in methanol $(10 \mathrm{~mL})$ as mother solution. Dilution of mother solution with methanol gave various concentrations of TPZs $\left(1 \times 10^{-3}, 5 \times 10^{-4}, 4 \times 10^{-4}\right.$, $\left.2 \times 10^{-4}, 1 \times 10^{-4}, 8 \times 10^{-5}, 5 \times 10^{-5}, 4 \times 10^{-5}, 2 \times 10^{-5}, 1 \times 10^{-5} \mathrm{M}\right)$. The absorption spectra of the resulting TPZs solutions $(100 \mu \mathrm{L})$ were measured. The dependence of absorbance at $460 \mathrm{~nm}$ on TPZs concentration is shown in Figure S1 as a standard curve.

The measurement of TPZs concentration in TPZsmodified AuNPs mother solution

The concentration of TPZs-modified AuNPs (TPZs-AuNPs) stock was measured by ICP-AES (TJA Co., Franklin, MA, USA). A TPZs-AuNPs solution $(0.5 \mathrm{~mL})$ at gold concentration of $3,652 \mathrm{mg} / \mathrm{mL}(18.54 \mathrm{mM})$ was dissolved in aqua regia $(0.5 \mathrm{~mL})$ and diluted with methanol $(4.0 \mathrm{~mL})$. The absorbance at $460 \mathrm{~nm}$ of the resulting TPZs solution $(100 \mu \mathrm{L})$ was 0.07958 . The concentration of TPZs in the solution under measurement was $1.349 \times 10^{-5} \mathrm{M}$, calculated using an external standard method. In the stock TPZs-AuNPs solution, the TPZs concentration was $1.349 \times 10^{-4} \mathrm{M}$.

\section{The calculation of TPZs number in TPZs-AuNPs}

According to the reference, the number of gold atoms in a $15 \mathrm{~nm}$ gold nanoparticle was $\sim 100,594$. In the mother solution, the gold concentration was $18.54 \mathrm{mM}$, and the concentration of TPZs was $1.349 \times 10^{-4} \mathrm{M}$. Thus, the calculated number ratio of TPZs to AuNPs was 732:1. 


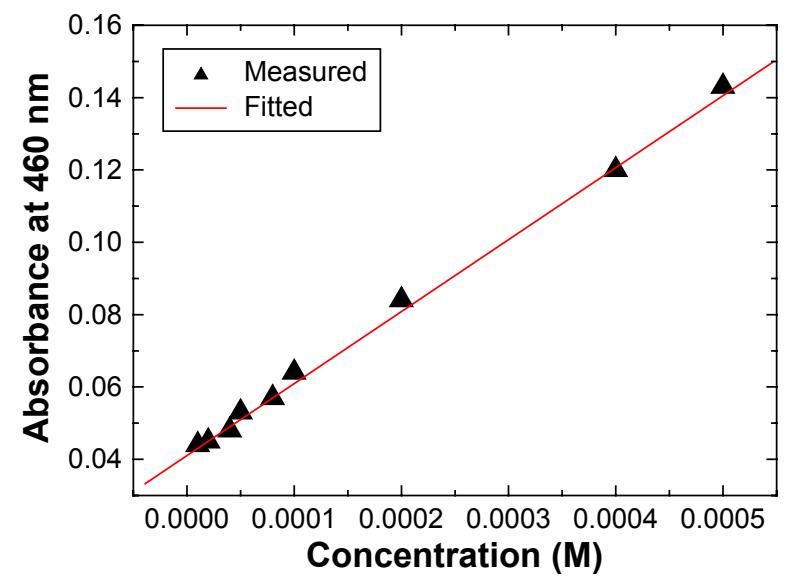

Figure SI The absorbance at $460 \mathrm{~nm}$ of TPZs methanol aqueous solution at various concentrations. Abbreviation: TPZs, thioctyl tirapazamine.

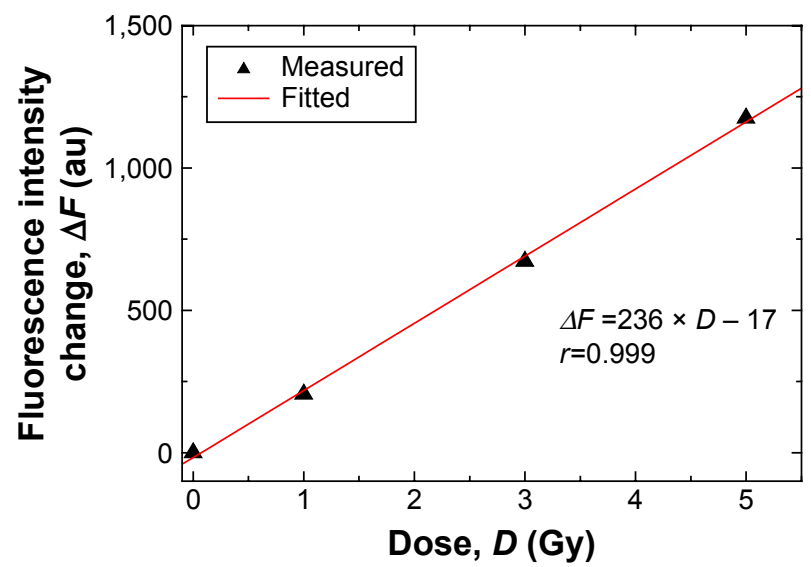

Figure $\mathbf{S} 2$ The dependence of fluorescence intensity change on the dose of $\mathrm{X}$-rays $\left(50 \mathrm{k} \mathrm{V}_{\mathrm{p}}\right)$.

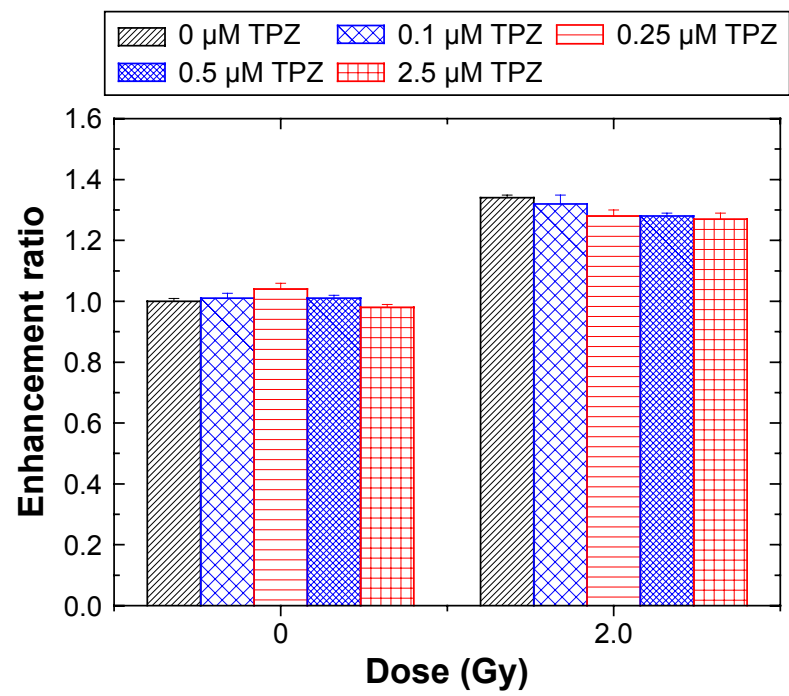

Figure S3 The enhancement ratio of hydroxyl radical production induced by tirapazamine under X-ray irradiation. Abbreviation: TPZ, tirapazamine. 

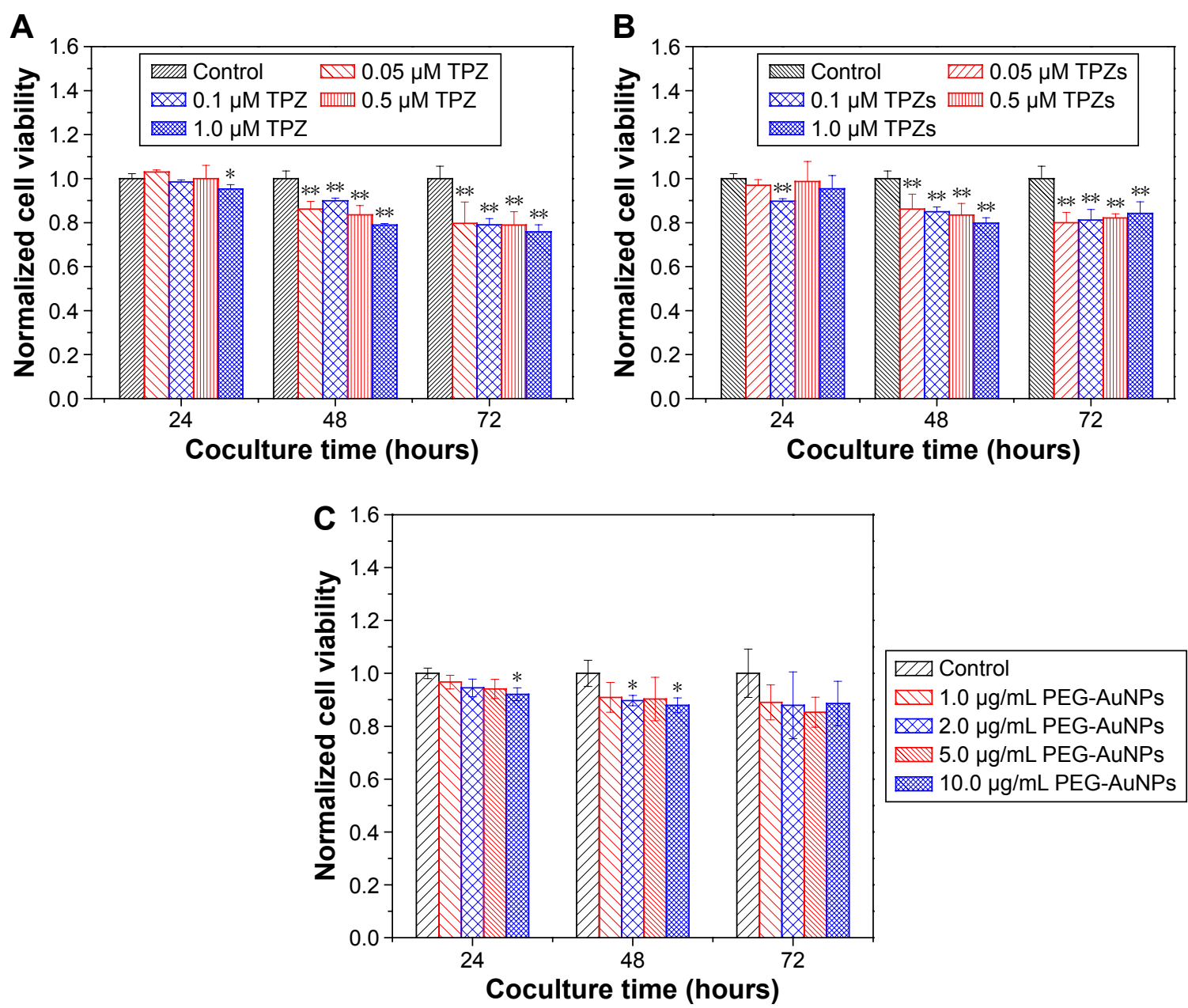

Z7] Control

$\triangle 1.0 \mu \mathrm{g} / \mathrm{mL}$ PEG-AuNPs $\triangle X \triangle 2.0 \mu \mathrm{g} / \mathrm{mL}$ PEG-AuNPs חIN $5.0 \mu \mathrm{g} / \mathrm{mL}$ PEG-AuNPs $10.0 \mu \mathrm{g} / \mathrm{mL}$ PEG-AuNPs

Figure S4 The Cytotoxicity of TPZ, TPZs and PEG-AuNPs.

Notes: The normalized cell viability of HepG2 cells cocultured with (A) TPZ, (B) TPZs, and (C) PEG-AuNPs at various concentrations relative to that of untreated HepG2 cells at 24,48 , and 72 hours. $* P<0.05$ and $* * P<0.01$, determined by the two-tailed Student's $t$-test.

Abbreviations: TPZ, tirapazamine; TPZs, thioctyl tirapazamine; PEG-AuNPs, polyethylene glycol-capped gold nanoparticles.



Figure S5 The enhancement ratio of ROS in HepG2 cells after X-ray irradiation in the presence of PEG-AuNPs $(20.0 \mu \mathrm{g} / \mathrm{mL}) \mathrm{and}$ TPZs-AuNPs $(5.0 \mu \mathrm{g} / \mathrm{mL})$. Note: $* * P<0.01$ versus control group, determined by the two-tailed Student's $t$-test.

Abbreviations: ROS, reactive oxygen species; PEG-AuNPs, polyethylene glycol-capped gold nanoparticles; TPZs-AuNPs, thioctyl tirapazamine-modified gold nanoparticles; AuNPs, gold nanoparticles. 
International Journal of Nanomedicine

Dovepress

\section{Publish your work in this journal}

The International Journal of Nanomedicine is an international, peerreviewed journal focusing on the application of nanotechnology in diagnostics, therapeutics, and drug delivery systems throughou the biomedical field. This journal is indexed on PubMed Central, MedLine, CAS, SciSearch ${ }^{\circledR}$, Current Contents ${ }^{\circledR} /$ Clinical Medicine,
Journal Citation Reports/Science Edition, EMBase, Scopus and the Elsevier Bibliographic databases. The manuscript management system is completely online and includes a very quick and fair peer-review system, which is all easy to use. Visit http://www.dovepress.com/ testimonials.php to read real quotes from published authors.

Submit your manuscript here: http://www.dovepress.com/international-journal-of-nanomedicine-journal 